\title{
Nutritional therapy and infectious diseases: a two-edged sword
} Haig Donabedian*

\author{
Address: Professor of Medicine, College of Medicine, University of Toledo, 3120 Glendale Avenue, Toledo, OH 43614, USA \\ Email: Haig Donabedian* - haig.donabedian@utoledo.edu \\ * Corresponding author
}

Published: 04 September 2006

Nutrition Journal 2006, 5:21 doi:10.1 |86/1475-289/-5-21

This article is available from: http://www.nutritionj.com/content/5/I/2

(C) 2006 Donabedian; licensee BioMed Central Ltd.

This is an Open Access article distributed under the terms of the Creative Commons Attribution License (http://creativecommons.org/licenses/by/2.0), which permits unrestricted use, distribution, and reproduction in any medium, provided the original work is properly cited.
Received: 05 April 2006

Accepted: 04 September 2006

\begin{abstract}
The benefits and risks of nutritional therapies in the prevention and management of infectious diseases in the developed world are reviewed. There is strong evidence that early enteral feeding of patients prevents infections in a variety of traumatic and surgical illnesses. There is, however, little support for similar early feeding in medical illnesses. Parenteral nutrition increases the risk of infection when compared to enteral feeding or delayed nutrition. The use of gastric feedings appears to be as safe and effective as small bowel feedings. Dietary supplementation with glutamine appears to lower the risk of post-surgical infections and the ingestion of cranberry products has value in preventing urinary tract infections in women.
\end{abstract}

\section{Background}

One of the earliest responses to infection is cytokinemediated anorexia. Interleukins $1,6,8$ as well as tumor necrosis factor and interferon alpha are released by host defense mechanisms. These cytokines reduce nutrient intake through effects on the central nervous system [1]. They also cause the sequestration of critical nutrients such as iron, copper and zinc in order to allow the host to gain an advantage over invading organisms [2]. Is it a benefit to bypass the action of the body's host defense mechanisms by feeding patients who do not or cannot ingest their normal diet?

The developed world is rife with calories and nutrients. Is there a benefit from nutritional supplements in preventing infections in societies where the availability of nutrients is not limited?

Physicians are often asked about the role of various nutritional interventions in preventing or treating infectious diseases. What is known about the value of these interventions?
This review will not deal with nutritional interventions in populations which often suffer dietary deficiencies. As such, it will include only studies done in economically developed nations. Finally, it will review the use of cranberry products and yogurt as these are available in any grocery store, but not the myriad of botanical products sold for their medicinal value.

In order to clarify what is known about the risks and benefits of nutrition in the developed world, I have reviewed the English language publications available on MEDLINE (1966-2006) and in the Cochrane Library which deal with nutrition and infection. All articles including the words "nutrition", "vitamin(s)", "cranberry" or "yogurt" and the words "infection" or "infectious" in their abstracts were reviewed. Articles were included if they were structured to compare differing nutritional interventions.

Prevention of infection in the general population and the institutionalized

Is nutritional therapy of value in preventing infectious diseases in the developed world? There is a large body of evi- 
dence that supports the thesis that insufficient intake of dietary protein adversely affects the immune system and predisposes the malnourished to infectious diseases [3-5]. This inadequate protein intake is usually coupled with reduced intake of calories and is referred to as protein-calorie malnutrition (PCM).

\section{Protein}

Since there are no prospective studies in which protein intake is manipulated in order to assess infection risk in non-hospitalized people, indirect studies must be evaluated. The use of serum albumin as an indicator of protein intake is fraught with problems as chronic illnesses in themselves may prevent adequate protein intake and may inhibit the synthesis of albumin [6].

Preoperative albumin levels have been shown to correlate with the postoperative risk for pneumonia, urinary tract infections and wound infections in a large Veterans Administration study [7]. This study did not deal directly with nutrition, however. A more relevant study looked at 1,023 acute trauma patients admitted to a Baltimore hospital. Since these patients were acutely ill due to a nonmedical condition, their albumin levels were more likely to reflect previous nutritional status rather than previous medical illness. There was a $48 \%$ incidence of infection in those admitted with a serum albumin of less than 2.6 $\mathrm{gms} / \mathrm{dL}$ and a $28 \%$ incidence in those with an albumin of $2.6 \mathrm{gms} / \mathrm{dL}$ or above $(\mathrm{p}<0.001)$. The infections were predominately respiratory and urinary in nature [8].

This evidence indirectly supports adequate protein intake as a factor in preventing infections after trauma.

\section{Multivitamins and zinc}

Studies have shown that most elderly patients fail to ingest the recommended daily allowance (RDA) of zinc. Supplementation with zinc could improve their immune responses to infection and thus prevent illness. Zinc supplementation for people aged 60-89 (defined as elderly) alone increased their in vitro lymphocytes' response to mitogens [9]. Their response to skin test antigens however, was not increased. When $15 \mathrm{mg}$ of zinc was added to a multivitamin preparation and compared to a lactose placebo given to people aged 59-85 living in northern New Jersey, there was a significant increase in skin test responses to a panel of seven intradermal antigens [10]. The incidence of infectious diseases was not studied.

There is a considerable literature concerning the use of zinc as a therapy for the common cold. Marshall has reviewed 8 such studies and concludes that there is no convincing evidence as to zinc's efficacy in reducing the severity or duration of cold symptoms [11].
There is evidence that zinc supplementation significantly reduces the incidence of infections in people with sickle cell disease. Twenty-one of 32 sickle cell disease patients in the Detroit area were found to have zinc deficiency as determined by lymphocyte or granulocyte zinc levels. Zinc supplementation in those deficient reduced their documented infection rate by as much as $80 \%$ [12]. Their hospitalization rate, however, was unaffected.

Multivitamin and mineral supplementation has not been shown to affect illness or absenteeism rates in 158 adults (age $>45$ years old) living in North Carolina unless they had type II diabetes [13]. Diabetics taking a placebo reported a 93\% incidence of infection (as opposed to an incidence in non-diabetics of $60 \%$ ). Strangely, diabetics taking supplementation showed only a $17 \%$ incidence of infection-much lower than non-diabetics taking placebo. The infections did not result in hospitalizations. Elderly people ( $>60$ years old) living in central France had no decrease in infection incidence when receiving a multivitamin supplementation as compared to a placebo [14]. A prospective study relating the intake of carotenoids, vitamins $\mathrm{C}$ and $\mathrm{E}$ and $\mathrm{B}$-vitamins with the incidence of community acquired pneumonia in over 50,000 U. S. male health professionals aged 40-75 years old failed to show any correlation between pneumonia risk and vitamin intake [15]. This study looked at both food and supplement sources of vitamins. "Natural" vitamins therefore seemed to be no better than "pharmaceutical" vitamins in preventing pneumonia in this well-educated population of American men. Elderly nursing home residents in the Boston area were given multivitamins with either 4 IU of vitamin $\mathrm{E}$ ( $50 \%$ of the RDA) or $200 \mathrm{IU}$ of vitamin E. High intake of vitamin $\mathrm{E}$ had no effect on the incidence or duration of lower respiratory tract infection [16]. There appeared to be a small, but significant effect on the incidence of upper respiratory tract infections (including otitis media), but not on their duration (risk ratio $=0.84$ for incidence, but 1.53 for duration).

There are two studies which support the use of vitamin or micronutrient supplementation to prevent communityacquired infections. Chandra [17] showed that trace elements and multivitamins reduce the number of days with any sort of infection. The study enrolled 96 elderly Newfoundland residents and is apparently the only other study to show such an effect in those not institutionalized.

A French study gave a placebo, zinc and selenium supplements, or multivitamins with zinc and selenium to institutionalized people over the age of 65 [18]. The sample size was a total of 81 and over a two year follow-up period, they found that the number of pneumonias and UTIs decreased by about $50 \%$ in those who received the 
zinc and selenium with or without multivitamins. The multivitamins had no statistically significant effect alone.

If there is little or no effect of micronutrient and multivitamin supplementation on infection rates on apparently uninfected members of the community, how about those chronically infected with viruses? A small study from the era prior to the availability of effective anti-HIV therapy studied nutrient and vitamin intake in 56 HIV infected New Yorkers. Vitamin intake varied from $2 \%$ to $50,000 \%$ of the RDA. No correlation could be found between nutrient intake and CD4 lymphocyte count or absolute lymphocyte count [19].

A more intriguing study of HIV-infected people in Baltimore correlated their micronutrient intake as estimated by data from a questionnaire and the subsequent progression of HIV disease [20]. This study did not take any changing dietary habits into account. The study correlated any intake of zinc supplements with decreased survival. High intake of vitamins $B_{1}, B_{2}$ and $B_{6}$ were correlated with increased survival. Studies of this nature always raise the question of whether the increased intake reflected a healthier life style or produced a healthier life. A review of fifteen studies utilizing vitamin and micronutrient supplementation in HIV-infected people concluded that such supplementation effected no reduction in mortality or morbidity in HIV-infected adults. HIV-infected children in under-developed countries could benefit from vitamin A supplementation, however [21].

Hepatitis C has a prevalence between $1 \%$ and $2 \%$ in the U. S. population. Could nutritional therapy affect the progression to cirrhosis or hepatoma? The only vitamin supplementation studies done with hepatitis $\mathrm{C}$ involve the use of vitamin $\mathrm{E}$ as an anti-oxidant to limit hepatic fibrosis [22]. Two studies which show decreased transaminase levels when patients with hepatitis $C$ are given supplemental vitamin $\mathrm{E}[23,24]$ although there is no data on vitamin E's effect on the viral load.

\section{Vitamin C}

The RDA for vitamin $\mathrm{C}$ is between 45 and $60 \mathrm{mg}$ per day. The writings of Linus Pauling have popularized the use of vitamin $\mathrm{C}$ as a prophylactic and therapeutic agent for the common cold [25]. The nutritional value of a vitamin ingested at more than 10 times its RDA begs the question of whether the vitamin is nutritional or pharmacologic. A comprehensive meta-analysis has been published [26] which finds that huge doses of vitamin $\mathrm{C}$ have a minimal effect on reducing cold symptoms. No effect on cold prevention could be found unless groups undergoing hypothermic stress were studied.
There is a published study which supplemented British patients over the age of 65 with a placebo or $200 \mathrm{mg}$ of vitamin $\mathrm{C}$ if they were admitted to hospital with bronchitis or pneumonia [27]. The patients were followed for 4 weeks. If patients who died were excluded from the analysis, the study showed that vitamin $\mathrm{C}$ administration lessened the symptom score of surviving patients. Only one of the six deaths in the study occurred in a vitamin $\mathrm{C}$ recipient, but the sample size was too small $(n=57)$ to show significance.

\section{Cranberry juice}

Many people believe that drinking cranberry juice will treat or prevent urinary tract infections. There is evidence that cranberry juice contains anti-adhesive molecules which could interfere with bacterial virulence mechanisms [28]. Cranberry juice (300 ml/day) or a colored drink containing no cranberry products were provided to female residents of a long-term care facility in Boston [29]. Monthly urine samples were analyzed. At one month, the percentage of urine samples with more than $100,000 \mathrm{CFU} / \mathrm{ml}$ of urine was identical whether or not cranberry juice was ingested. After one month, there was a consistent decrease in high-grade bacteriuria in the cranberry juice drinkers. The calculated relative risk for bacteriuria with pyuria for cranberry drinkers was $0.42(\mathrm{p}=$ $0.0004)$. Antibiotic use for UTI was almost halved in those drinking cranberry juice. In this study, the distinction between UTI prevention and treatment is unclear, but its ability to obviate the use of antibiotics is significant.

A Canadian study randomized 150 sexually active women who had $\geq 2$ UTIs in the previous year into three groups: 1) $250 \mathrm{ml}$ of diluted pineapple juice (colored red) thrice daily and a placebo tablet twice daily; 2) A concentrated cranberry extract tablet twice daily and placebo juice; 3 ) $250 \mathrm{ml}$ of cranberry juice thrice daily and a placebo tablet [30]. The study continued for a year. Symptomatic infections were treated with antibiotics for 3 days and the prophylaxis restarted. The placebo group showed $32 \%$ of entrants with at least one UTI during the year of study. The tablet group had $18 \%$ with at least one infection and the cranberry juice group had $20 \%$. The difference between the tablet or juice groups and placebo was significant $(\mathrm{p}<$ $0.05)$. The mean number of UTIs per year was approximately halved by the use of a cranberry product.

The daily ingestion of cranberry juice concentrate or a placebo did not affect bacteriuria rates in children requiring intermittent catheterization [31].

There is sufficient reason based on these two positive studies and others reviewed by Raz et al [29] to recommend a cranberry product to women with recurrent UTIs. 
Table I: Summary of randomized, controlled trials of the impact of nutritional interventions on infections in the non-hospitalized population

\begin{tabular}{llc}
\hline Intervention & Effect & Reference \\
\hline Zinc supplementation & No effect on common colds & 11 \\
Zinc supplementation & reduced infection incidence in sickle cell patients & 12 \\
Zinc and selenium supplementation & Reduced infection incidence & 18 \\
Vitamin and mineral supplementation & Reduced infection incidence in type II diabetics only & 13 \\
Vitamin and mineral supplementation & Reduced infection incidence & 17 \\
Multivitamin supplements & No effect on infection incidence & 14 \\
Multivitamin supplements & No effect on pneumonia incidence & 15 \\
Vitamin E supplements & Reduced URI rate, no effect on lower respiratory tract rate & 16 \\
Vitamin C therapy or supplements & No effect on common cold unless used in hypothermic conditions & 26 \\
Cranberry juice & Reduced incidence of bacteriuria & 29,30 \\
Yogurt & Reduced diarrhea incidence in adults taking antibiotics & 32 \\
Yogurt & No effect on diarrhea incidence & 33 \\
Lactobacilli & Reduced incidence of diarrhea in children \\
Lactobacilli & No effect on diarrhea incidence in adults & $34-36$
\end{tabular}

\section{Yogurt}

Yogurt is cow's milk usually fermented using two synergistic bacterial species Lactobacillus delbrueckii subspecies bulgaricus and Streptococcus thermophilus. The amount of fat and even the bacteria used to ferment the milk may vary from study to study. The presence or absence of living bacteria must be kept in mind when evaluating studies which employ yogurt. There are few randomized studies in which yogurt (as opposed to lactobacilli or yeast in pure form) is administered in the developed world. Beniwal et al gave 109 American patients 227 grams of vanilla flavored yogurt twice daily for 8 days if they were receiving intravenous or oral antibiotics [32]. The yogurt contained L. acidophilus as well as L. bulgaricus and S. thermophilus. The control group of 97 patients received no yogurt. The mean number of days of yogurt intake was 6.6 days. Diarrhea as defined by 3 or more loose bowel movements per day was reported in 13\% of yogurt ingesters and 23\% of those not eating yogurt. The duration of diarrhea was not significantly decreased. Israeli soldiers eating yogurt with living $L$. casei did not have fewer diarrheal episodes than those soldiers eating yogurt containing no living bacteria [33]. The study had approximately 250 soldiers in each arm and the mean incidence of diarrhea was $14 \%$. If there were an undetected effect, it would have had to be a small one.

While not a nutritional therapy per se lactobacilli are used by those who do not tolerate yogurt or find it unfeasible. Lactobacillus casei strain GG was administered in capsules (not yogurt) to American children receiving concurrent antibiotics. The living bacteria reduced the percentage of children with diarrhea (defined as more than one liquid stool/day) from 26 to $8 \%$ when compared to an inulin placebo [34]. A Finnish study using Lactobacillus strain GG found that recovery from diarrhea was one day quicker on average in those children that received living bacteria in capsular form as opposed to children who received a placebo [35]. The same Lactobacillus casei strain reduced the incidence of antibiotic-associated diarrhea in Finnish children from $16 \%$ to $5 \%$ [36].

When the effect of the same GG strain was used to prevent antibiotic associated diarrhea in American adults, the results were disappointing. A study analyzed 268 hospitalized patients and found almost identical diarrhea rates and frequencies in those receiving the live bacteria and in those receiving a placebo [37].

The "non pathogenic" yeast Saccharomyces boulardii has been shown to reduce antibiotic-related diarrhea in hospitalized Americans when administered in capsule form [38]. Enthusiasm for this therapy has waned due to reports such as that of 7 French patients who developed fungemia after ingesting this yeast in the setting of an intensive care unit [39].

The ability of yogurt or lactobacilli to prevent diarrhea is still in question. Should yogurt contain living bacteria? Do the species of bacteria matter? Can yogurt be made with skim milk? Does the flavoring matter? How much yogurt should be ingested? These questions probably will never be answered. At present, yogurt cannot be recommended as a proven method of diarrhea prevention.

Table 1 summarizes the effects of various nutritional interventions on infections in the general population and in institutionalized people. 


\section{Pre-operative nutrition}

If the value of nutritional supplementation in the general citizenry of developed countries is unproven, how about for those about to undergo surgery?

A pre-operative cohort of 192 malnourished American veterans were randomized to receive total parenteral nutrition (TPN) and 203 control malnourished patients received conventional nutrition [40]. Malnutrition was defined by serum albumin or prealbumin levels, by a body weight $\leq 95 \%$ of ideal or a score $\leq 100$ on the Nutrition Risk Index. The Nutrition Risk Index uses body weight and serum albumin to calculate a malnutrition score. The TPN patients received therapy for at least seven preoperative days whereas the conventional patients went to surgery within 3 days. The TPN patients received TPN postoperatively for at least 72 hours. Conventional patients received no parenteral or enteral post operative feedings for 72 hours. After that time, they could receive whatever form of nutrition thought best. Overall infectious risk in a 30 -day post operative period was $14.1 \%$ in the TPN group and $6.4 \%$ in the conventional group $(\mathrm{p}=$ $0.01)$. The bacteremia/fungemia rates for TPN patients were $4.2 \%$ vs $2.5 \%$ and the rate of pneumonias was almost double that of the conventional group when patients were stratified by degree of malnutrition. The most severely malnourished TPN patients had a $12.9 \%$ infectious complication rate as opposed to a $10.5 \%$ rate in the severely malnourished conventional patients. The preoperative TPN course did not therefore ameliorate the infectious risk-if anything it exacerbated it.

\section{Early vs. late nutrition}

Patients who have undergone trauma or surgery need to be fed eventually. Would early feeding prevent or increase the rate of infections? There are several studies that examine various subsets of these patients.

Nasojejunal tubes were placed in 17 Arizona head trauma patients and feeding started within 36 hours of admission [41]. Feeding of the 15 control patients was by the nasogastric route and never before 72 hours. The patients were studied only for 7 days after admission. In this short time period, there were 14 infections in the late feeding group and only 3 in the early feeding group. The predominant infection was "bronchitis" - a diagnosis whose criteria were not defined. Since this study was not blinded, observer bias would be hard to eliminate. A similar study was done in Tennessee using 30 patients fed nasogastrically before 72 hours or after gastric ileus was resolved [42]. There was no difference in the incidence of pneumonia or infections in general. A small study enrolling cervical trauma patients also failed to show an advantage with early enteral feeding [43].
Sixty-three abdominal trauma patients requiring celiotomy were entered into a study in which half the patients received intravenous glucose for the first five post-operative days and the other half had an immediate percutaneous jejunal feeding tube placed through which was administered an elemental diet [44]. Patients fed immediately had a "sepsis" rate of $9 \%$ while those not fed for five days had a rate of $29 \%$ in the first seven days ( $p<0.05$ ). Unfortunately, "sepsis" was not further defined. A metaanalysis of early feeding in patients undergoing gastrointestinal surgery included 11 studies and 837 patients [45]. The patients were fed either orally or by jejunal feeding. Early was defined as within 24 hours of surgery. The relative risk of all infections was 0.72 in favor of early feeding. The risk of pneumonia was between 0.7 and 0.8 and the risk of intra-abdominal abscess was between 0.8 and 0.9. The rationale behind early enteral feeding in gastrointestinal surgery is based on the putative increase in intestinal epithelial health and decreased translocation of intestinal flora into the systemic circulation. Numerous studies seem to confirm early enteral feedings' value in abdominal surgery, whether or not the rationale is valid. The benefit of early feeding has not been found in acutely burned children who were fed within 24 hours of the burn as opposed to after 48 hours [46], but the mean difference of 33 hours in delaying nutrition cannot be said to be large.

A review of 15 studies incorporating abdominal surgery, trauma, head injury and burns came to the conclusion that early (within 36 hours) enteral feeding yielded a significantly decreased rate of infection (19\% vs $41 \% \mathrm{p}=$ $0.049)$. There was considerable heterogeneity amongst the studies, with abdominal surgery studies having the most convincing risk reduction [47].

The benefit of early feeding in trauma and surgery patients does not appear to generalize to early enteral feeding in those with severe medical illnesses.

The FOOD study looked at the benefit of early tube feeding in dysphagic stroke patients from around the world [48]. Four hundred and thirty patients were randomized to avoid any enteral tube feedings for 7 days as opposed to 429 allocated to nasogastric or percutaneous endoscopic gastrostomy (PEG) feeding within 3 days of enrollment. Early feeding had no effect on the rates of pneumonia or urinary tract infections. Nor was there an effect on survival by delaying feeding for seven days.

All patients ventilated in a St. Louis ICU received an orogastric tube. Early-fed patients $(n=75)$ received their nutritional requirements from day 1 , while the late fed ( $\mathrm{n}$ $=75$ ) patients received $20 \%$ of their requirements for 4 days and then their feedings were increased to their calculated optimal level [49]. The early feeding group had no 
fewer bacteremias or UTIs. The early feeding group had $65 \%$ more antibiotic days than the late feeding group ( $\mathrm{p}<$ 0.001 ) and their length of stay in the ICU was almost twice as long. Ventilator-associated pneumonias occurred in $37 \%$ of the early feeding group as opposed to $23 \%$ of the late feeding group $(\mathrm{p}=0.02)$. The size of this study and its' quality argues against an infectious benefit by early feeding of medical patients requiring ventilation.

\section{The route of nutrition delivery}

Is there significant benefit or risk associated with the route chosen for delivery of nutrition? Would total parenteral nutrition (TPN) increase the bacteremia rate, but decrease the incidence of aspiration pneumonia, for instance? Could jejunal feeding reduce the likelihood of esophageal reflux and thus lower the pneumonia rate when compared to gastric feeding?

\section{Gastric vs non-gastric enteral feeding}

Gastrostomy feeding of 10 neurologically dysphagic patients was compared to 20 fed by nasogastric tube in Scotland [50]. The nasogastric tube was a "fine bore" 20 French tube. After 28 days, the gastrostomy patient group suffered two aspiration pneumonias and one wound infection versus no pneumonias for the nasogastric group. Another small study compared ventilated Canadian trauma patients receiving gastric versus duodenal feedings via nasal or oral tubes. Forty three gastrically fed patients had 18 clinically diagnosed pneumonias versus 10 pneumonias in the 37 patients receiving duodenal feedings. No difference was statistically discernible with the sample size used. Nasogastric and nasoduodenal feeding of ventilated patients was compared in 44 California medical ICU patients [51]. The pneumonia, bacteremia and mortality rates were indistinguishable.

Jejunal feedings were compared to gastric feedings in 38 Boston medical and surgical ICU patients. The jejunal tubes were placed perorally. About half of each group was ventilated. Two gastrically fed patients developed pneumonia versus none of the jejunally fed [52]. Such a small study is not convincing.

Two meta-analyses have been published which analyzed the differences between gastric and non-gastric enteral feeding. One [53] found a relative risk of 0.76 of developing a pneumonia for small bowel (duodenal or jejunal) feedings. The other [54] found no proven benefit in preventing pneumonia by employing small bowel feedings. The consensus statement of a North American summit on aspiration in critically ill patients likewise concluded that good evidence does not exist for small bowel feedings unless proven aspiration occurs and then jejunal feedings were recommended [55]. This consensus group did recommend continuous enteral feeding rather than bolus feeding apparently based on the study carried out on 60 Nebraskan patients receiving nasogastric feedings [56]. This study only followed elderly patients for seven days. All patients were assessed clinically for aspiration and continuously fed patients had one-half the aspiration rate of intermittently fed patients. This difference was not statistically significant.

\section{TPN vs enteral nutrition}

There are many small trials in various sub-groups of patients (i.e.: lymphoma, radiotherapy) comparing enteral and total parenteral nutrition. This review will discuss only meta-analyses of various subgroups for the sake of brevity as the findings are remarkably homogenous. A large meta-analysis of 7 studies comparing TPN with standard care and 20 studies comparing tube feeding to TPN was done by Braunschweig et al [57]. A total of 1,828 patients were included in these randomized prospective studies. Standard care patients had a relative risk of infection of 0.77 when compared to TPN and enterally fed patients had a relative infection risk of 0.66 . If catheter infections were excluded from the meta-analysis, the increased risk of infection associated with TPN persisted.

A much smaller meta-analysis using mostly unpublished studies was done on 230 surgical and trauma patients [58]. The overall risk of infection complications was 2.5 times higher $(p=0.0001)$ in those randomized to TPN as opposed to enteral feedings early in the course of hospitalization. Rather than increasing the risk of aspiration and pneumonia, enteral feedings reduced that overall risk of pneumonia to $40 \%$ of that seen in TPN patients.

Since pancreatitis causes severe inflammation which may lead to transluminal spread of bacteria, it would be reasonable to suppose that TPN would decrease the infectious risks in patients with pancreatitis by decreasing pancreatic activity. The combined risk for infection for pancreatitis patients in two trials $(\mathrm{n}=70)$ of enteral feeding was 0.61 when compared to the TPN route [59].

Chemotherapy patients may have long periods of anorexia and poor nutrition. Would TPN mitigate this malnutrition and allow a more vigorous defense against infection? Many small studies examining this question were published in the 1980's and 1990's. None showed an infection benefit with TPN. A meta-analysis of 15 studies comparing TPN with routine care was published in 1990 [60]. Three month survival and chemotherapy response were not improved by the use of TPN. The risk of infection was 3.2 times higher in those receiving TPN ( $\mathrm{p}<$ $0.005)$ even if catheter-related infections were excluded from the analysis. If catheter infections were included, the risk of infection was 4 times greater in those receiving TPN. A recent Brazilian study [61] found that a central 
venous catheter through which TPN was given had a 3.3 times greater risk of becoming infected than a similar catheter not used for TPN.

Is the flood of intravenous nutrients responsible for the increased rate of infections seen with TPN or is it the lack of enteral feeding and the presence of a central venous catheter? Some insight into the answer is gained by the result of studies comparing TPN with intravenous feedings of other types.

A study of 248 Swedish post-operative patients were randomized to TPN or glucose and electrolyte solutions until they could eat and drink "freely" without the use of any intravenous support [62]. They found that those supported with glucose and electrolytes had a 5\% mortality as opposed to $2 \%$ with TPN, but this difference was not significant. Both groups had similar rates of wound infections and pneumonia. Similar results were seen in 117 post-pancreatic resection patients in New York [63].

Reducing the amount of glucose and protein in the TPN admixture did not affect the infection rate in 40 patients with a variety of underlying conditions. Six of 21 hypocaloric TPN patients developed infections as did 10 of 19 standard TPN patients. This difference is not statistically significant due to the small sample size [64]. Thus, there is no data to support the idea that increased delivery of nutrients intravenously alone increases the rate of noncatheter infection, but the size of the samples and the duration of the TPN may be an important variable in these studies. Enteral feedings seem to protect against infection.

There are several potential explanations for this apparent protection provided by enteral feedings. There is evidence reviewed by Kudsk [65] that levels of IgA and numbers of circulating lymphocytes from gut-associated lymphoid tissue are strongly affected by enteral feeding. These lymphocytes migrate to non-gut tissues such as the lung and can alter the immune response in non-gut locales. The neuroendocrine system of the gut also affects the regulation of inflammation outside of the gut. This neuroendocrine system is modulated by the presence of dietary constituents $[66,67]$. The value of enteral feeding may be thus dependent on cellular and neuroendocrine factors.

\section{The value of nutritional supplements in the critically ill}

There are many nutritional additives which are hypothesized to improve host defenses by boosting immunity and are called by some immuno-nutrients [68]. A meta-analysis compared published studies using two different "immunologically enhanced" enteral feedings with standard enteral feeding mixtures. These two "enhanced" mixtures had increased amounts of arginine, omega- 3 fatty acids and nucleotides when compared with standard feed- ings. One of the feeding mixtures had added glutamine as well [69]. All studies analyzed enrolled critically ill medical and surgical patients. Although there was no detectable mortality benefit to enhanced feedings, there was an overall reduction in infectious risk to $0.60(\mathrm{p}<0.005)$. No statistically significant infectious benefit could be found if only medical patients were analyzed $(p=0.30)$.

When studies enrolling only cancer patients are analyzed, no significant benefit of enhanced enteral nutrition was found in reducing nosocomial pneumonia. Effects on other infections were not analyzed. There was no significant effect of enhanced feeding on length of hospital stay or mortality [70]. If the enhanced feedings were started 7 days before cancer surgery and continued after the surgery, there was evidence of an infectious benefit in 206 Italian patients [71]. The pneumonia rate was more than twice as high in those receiving non-enhanced nutrition and the overall infection in the standard nutrition group was $30 \%$ compared to $14 \%$ in the enhanced nutrition group $(\mathrm{p}=0.009)$.

When a routine hospital diet feeding was compared with a diet supplemented with 22.5 grams of extra protein and extra calories, there was no infectious risk benefit for stroke patients. A large multinational trial involving 4,023 patients showed no difference in pneumonia or urinary tract infection rates. The rate of developing pressure ulcers was not altered by supplementation either [72].

An innovative form of nutritional supplement was given to Hungarian patients with pancreatitis [73]. Twentythree control and 22 experimental patients received nasojejunal feedings for 7-10 days. The control group also received 10 grams of oat fiber twice a day as well as 10 billion heat-killed Lactobacillus plantarum. The experimental group received the oat fiber and living bacteria. Seven control patients and only 1 experimental patient had a positive pancreatic aspiration culture $(\mathrm{p}=0.05)$. Seven control patients required surgery to control sepsis compared to one experimental patient. The hypothesis that the composition of the enteral flora affects the rate of sepsis is supported by this study.

There is considerable literature regarding the amino acid glutamine's ability to preserve enterocyte integrity and reduce bacterial translocation from the gut [74]. When Dutch trauma patients received enteral nutrition or glutamine-supplemented enteral nutrition (which was iso-nitrogenous and iso-caloric), the glutamine supplemented group showed a definite infectious benefit [75]. There were fewer pneumonias ( $17 \%$ vs $43 \%$ ) and bacteremias (9\% vs 38\%). A study of Spanish ICU patients with systemic inflammatory response syndrome yielded similar results for enteral glutamine supplementation [76]. 
Table 2: Summary of randomized, controlled trials on the impact of nutritional interventions on infections in hospitalized patients

\begin{tabular}{llc}
\hline Intervention & Effect & Reference \\
\hline Preoperative TPN & Increased infection incidence & 40 \\
Early vs late enteral nutrition & Decreased rate of infection in trauma and surgical patients & $4 I, 44,45,47$ \\
Early vs late enteral nutrition & No effect on infection incidence in stroke patients & 48 \\
Early vs late enteral nutrition & Increased infection rate in intubated patients in medical ICU & 49 \\
TPN vs enteral nutrition & Increased rate of infections & $57-60$ \\
Immunologic feedings & No effect on infection incidence & $70-72$ \\
Glutamine supplementation & Decreased infection incidence & $75-78$
\end{tabular}

The pneumonia incidence was about halved in the glutamine group $(\mathrm{p}=0.04)$, although the incidence of bacteremia was unaffected by glutamine supplementation.

Glutamine need not apparently be given enterally to detect an infectious benefit. Burn patients receiving intravenous glutamine were compared with those receiving an iso-nitrogenous amino acid mixture. Only 1 of 12 glutamine patients had a Gram-negative bacteremia compared to 6 of 14 control patients ( $p=0.04$ ). The Grampositive bacteremia and fungemia rates were unaffected by glutamine infusion [77]. Intravenous supplementation glutamine decreased bacteremias in bone marrow transplant patients when compared with parenteral nutrition without glutamine supplementation [78].

Table 2 summarizes the effect of various nutritional interventions on infections in hospitalized patients.

\section{Conclusion}

The literature concerning nutrition and infectious diseases in the developed world contains mixed support for ideas that nutritional supplements serve to prevent infectious diseases. While there is good evidence that enterally feeding those who have sustained surgical or accidental trauma prevents infections, other circumstances may implicate nutrition as a risk factor for infection rather than as a benefit. The following general points can be supported:

1. There is inconsistent evidence that healthy elderly and diabetic people can decrease their infectious risk by taking multivitamins and micronutrient supplementation. 2. Cranberry juice or concentrate can reduce bacteruria in
women.

3. Yogurt or lactobacilli have an inconsistent effect in treating or preventing diarrhea.

4. Nutritional supplements offer little benefit in preventing infection in those already ill. The exception may be glutamine supplementation.
5. Enteral feeding is superior to parenteral feeding in lessening infectious risk.

6. Early enteral feeding in trauma and surgical patients prevents infections.

7. There is no best site for the delivery of enteral feedings. Gastric feedings do not appear to increase the risk of aspiration pneumonia when compared to small bowel feedings.

\section{References}

I. Plata-Salaman CR: Cytokines and feeding. Int J Obes Relat Metab Disord 200I, 25(supplement 5):548-552.

2. Mackowiak PA: Temperature regulation and the pathogenesis of fever. In Principles and Practice of Infectious Diseases 6th edition. Edited by: Mandell GL, Bennett JE, Dolin R. Philadelphia, Elsevier Churchill Livingstone; 2005:703-718.

3. Woodward B: Protein, calories and immune defenses. Nutr Rev 1998, 56:S84-S92.

4. Ford GW, Belbin R, Jose DG, Vorbash EA, Kirke DK: Growth and immune function in aboriginal children during recovery from malnutrition and infection. Aust NZJ Med 1976, 6:321-328.

5. Bienia R, Ratcliff S, Barbour GL, Kummer M: Malnutrition in the hospitalized geriatric patient. J Am Geriatric Soc 1982, 30:433-436.

6. Gabay C, Kuchner I: Acute-phase proteins and other systemic responses to inflammation. NEJM 1999, 340:448-454.

7. Gibbs J, Cull W, Henderson W, Daley J, Hur K, Khuri SF: Preoperative serum albumin level as a predictor of operative mortality and morbidity. Arch Surg 1999, 134:36-42.

8. Sung J, Bochicchio GV, Joshi M, et al.: Admission serum albumin is predictive of outcome in critically ill trauma patients. Am Surg 2004, 70: 1099-11102.

9. Bogden JD, Oleske JM, Lavenhar MA, et al: Effects of one year of supplementation with zinc and other micronutrients on cellular immunity in the elderly. J Am Coll Nutr 1990, 9:2 I4-225.

10. Bogden JA, Bendich A, Kemp FW, et al.: Daily micronutrient supplement supplements enhance delayed hypersensitivity skin test responses in older people. Am J Clin Nutr 1994, 60:437-447.

II. Marshall I: Zinc for the common cold. The Cochrane Database of Systematic Reviews 1999. Art. No. CD001364.

12. Prasad AS, Beck FWJ, Kaplan J, et al.: Effect of zinc supplementation on incidence of infections and hospital admissions in sickle cell disease (SCD). Am J Hematol 1999, 61: 194-202.

13. Barringer TA, Kirk JK, Santaniello AC, Foley KL, Michielutte R: Effect of a multivitamin and mineral supplement on infection and quality of life. Ann Int Med 2003, I38:365-37I.

14. Chavance M, Herbeth B, Lemoine A, Zhu BP: Does multivitamin supplementation prevent infections in healthy elderly subjects? Int J Vitam Nutr Res 1993, 63: I I-16.

15. Merchant AT, Curhan G, Bendich A, Singh VN, Willett WC, Fawzi WW: Vitamin intake is not associated with communityacquired pneumonia in US men. J Nutr 2004, 134:439-444.

16. Meydani SN, Leka LS, Fine BC, et al.: Vitamin E and respiratory tract infections in elderly nursing home residents. A randomized controlled trial. JAMA 2004, 292:828-836. 
17. Chandra RK: Effect of vitamin and trace-element supplementation on immune responses and infection in elderly patients. Lancet 1992, 340: I I24-II27.

18. Girodon F, Lombard M, Galan P, et al.: Effect of micronutrient supplementation on infection in institutionalized elderly subjects: A controlled trial. Ann Nutr Metab 1997, 41:98-107.

19. Luder E, Godfrey E, Godbold J, Simpson DM: Assessment of nutritional, clinical and immunologic status of HIV-infected, inner city patients with multiple risk factors. J Am Diet Assoc 1995, 95:655-660.

20. Tang AM, Graham NMH, Saah AJ: Effects of micronutrient intake on survival in human immunodeficiency virus type I infection. Am J Epidemiol 1996, I 43: I 244- 1256.

21. Irlam JH, Visser ME, Rollins N, Siegfried N: Micronutrient supplementation in children and adults with HIV infection (Review). The Cochrane Database of Systematic Reviews 2006. Art. No. CD003650

22. Coon JT, Ernst E: Complementary and alternative therapies in the treatment of chronic hepatitis C: a systematic review. J Hepatol 2004, 40:49I-500.

23. Von Herbay A, Stahl W, Niederan C, Sies H: Vitamin E improves the amino transferase status of patients suffering from vira hepatitis C: a randomized, double blind, placebo-controlled study. Free Radic Res 1997, 27:599-605.

24. Mahmood S, Yamada G, Niiyama G, et al.: Effect of vitamin $\mathbf{E}$ on serum amino transferase and thioredoxin levels in patients with viral hepatitis C. Free Radic Res 2003, 37:78I-785.

25. Hemila H: Vitamin C and the common cold. Brit J Nutr 1992 , 67:3-16.

26. Hemila H, Chalker E, D'Souza RRD, Douglas RM, Treacy B: Vitamin $C$ for preventing and treating the common cold. The Cochrane Database of Systematic Reviews 2004. Art. No. CD000980

27. Hunt C, Chakravorty NK, Annan G, Habibzaden N, Schorah CJ: The clinical effects of vitamin $C$ supplementation in elderly hospitalized patients with acute respiratory infections. Internat J Vit Nutr Res 1994, 64:212-219.

28. Raz $R$, Chazan $B$, Dan M: Cranberry juice and urinary tract infection. Clin Inf Dis 2004, 38:1413-1419.

29. Avorn J, Monane M, Gurwitz JH, et al.: Reduction of bacteriuria and pyuria after ingestion of cranberry juice. JAMA 1994, 271:751-754.

30. Stothers L: A randomized trial to evaluate effectiveness - and cost effectiveness of naturopathic cranberry products against urinary tract infection in women. Can J Urol 2002 9: I558- 1562.

31. Schlager TA, Anderson S, Trudell J, Hendley JO: Effect of cranberry juice on bacteriuria in children with neurogenic bladder receiving intermittent catheterization. I Pediatr 1999 I 35:698-702.

32. Beniwal RS, Arena VC, Leno T, et al.: A randomized trial of yogurt for prevention of antibiotic-associated diarrhea. Dig Dis Sci 2003, 48:2077-2082.

33. Pereg D, Kimhi O, Tirosh A, Orr N, Kayouf R, Lishner M: The effect of fermented yogurt on the prevention of diarrhea in a healthy adult population. Am J Infect Control 2005, 33:I22-I 25.

34. Vanderhoof JA, Whitney DB, Antonson DK, Hanner TL, Lupo JV, Young RJ: Lactobacillus GG in the prevention of antibioticassociated diarrhea in children. J Pediatr 1999, I 35:564-568.

35. Isolauri $E$, Juntunen $M$, Rautanen $T$, et al.: $\mathbf{A}$ human Lactobacillus strain (Lactobacillus casei sp strain GG) promotes recovery from acute diarrhea in children. Pediatrics |99|, 88:90-97.

36. Arvola T, Laiho K, Torkkeli S, et al.: Prophylactic Lactobacillus GG reduces antibiotic-associated diarrhea in children with respiratory infections: a randomized study. Pediatrics 1999, 1 04::e64.

37. Thomas MR, Litin SC, Osmon DR, et al.: Lack of effect of Lactobacillus GG on antibiotic-associated diarrhea: a randomized, placebo-controlled trial. Mayo Clin Proc 2001, 76:883-889.

38. Surawicz CM, Elmer GW, Speelman, et al.: Prevention of antibiotic-associated diarrhea by Saccharomyces boulardii: a prospective study. Gastroenterology 1989, 96:98I-988.

39. Lherm T, Monet C, Nougiere B, et al: Seven cases of fungemia with Saccharomyces boulardii in critically ill patients. Intensive Care Med 2002, 28:797-801.
40. Veterans Affairs Total Parenteral Nutrition: Cooperative Study Group, Perioperative total parenteral nutrition in surgical patients. NEJM 1991, 325:525-532.

4I. Grahm TW, Zadronzny DB, Harrington T: The benefits of early jejunal hyperalimentation in the head-injured patient. Neurosurgery 1989, 25:729-735.

42. Minard G, Kudsk KA, Melton S, Patton JH, Tolley EA: Early versus delayed feeding with an immune-enhancing diet in patients with severe head injuries. JPEN J Parenter Enteral Nutr 2000, 24: $145-149$

43. Dvorak MF, Noon VK, Belanger L, et al.: Early versus late enteral feeding in patient with acute cervical spinal cord injury. Spine 2004, 29:EI75-EI80.

44. Moore EE, Jones TN: Benefits of immediate jejunostomy feeding after major abdominal trauma- a prospective, randomized study. J Trauma 1986, 26:874-879.

45. Lewis SJ, Egger M, Sylvester PA, Thomas ST: Early enteral feeding versus "Nil by mouth" after gastrointestinal surgery: systematic review and meta-analysis of controlled trials. BMJ 200I, 323:773-776

46. Gottschlich MM, Jenkins ME, Mayes T, Khoury J, Kagan RJ, Warden GD: An evaluation of the safety of early versus delayed enteral support and effects on clinical, nutritional and endocrine outcomes after severe burns. J Burn Care Rehabil 2002, 23:40I-4I5

47. Marik PE, Zaloga GP: Early enteral nutrition in acutely il patients: a systematic review. Crit Care Med 200 I, 29:2264-2270.

48. The Food Trial Collaboration: Effect of timing and method of enteral tube feeding for dysphagic stroke patients (FOOD) : a multicenter randomized controlled trial. Lancet 2005, 365:764-77I.

49. Ibrahim EH, Mehringer L, Prentice D, et al.: Early versus late enteral feeding of mechanically ventilated patients: results of a clinical trial. JPEN J Parenter Enteral Nutr 2002, 26: I74- I8I.

50. Park RHR, Allison MC, Lang J, et al.: Randomized comparison of percutaneous endoscopic gastrostomy and nasogastric tube feeding in patients with persisting neurologic dysphagia. $B M$ 1992, 304:|406-|4||

5I. Kearns PJ, Chin D, Mueller L, Wallace K, Jensen WA, Kirsch CM: The incidence of ventilator-associated pneumonia and success in nutrient delivery with gastric versus small intestinal feeding: A randomized clinical trial. Crit Care Med 2000, 28: I 742- 1746.

52. Montecalvo MA, Steger KA, Farber HW, et al.: Nutritional outcome and pneumonia in critical care patients randomized to gastric versus jejunal tube feedings. Crit Care Mod 1992, 20:1377-1387.

53. Heyland DK, Drover JW, Dhaliwal R, Greenwood J: Optimizing the benefits and minimizing the risks of enteral nutrition in the critically ill: Role of small bowel feeding. JPEN 2002, 26:55I-557.

54. Collard HR, Saint S, Matthay MA: Prevention of ventilator-associated pneumonia: An evidence-based systematic review. Ann Int Med 2003, I 38:494-50I.

55. McClave SA, DeMeo MT, DeLegge MH, et al.: North American summit on aspiration in the critically ill patient: consensus statement. JPEN J Parenter Enteral Nutr 2002, 26:580-585.

56. Ciocon JO, Galindo-Ciocon DJ, Tiessen C, Galindo D: Continuous compared with intermittent tube feeding in the elderly. JPEN J Parenter Enteral Nutr 1992, I 6:525-528.

57. Braunschweig CL, Levy P, Sheean PM, Wang X: Enteral compared with parenteral nutrition: a meta-analysis. Am J Clin Nutr 200I, 74:534-542.

58. Moore FA, Feliciano DV, Andrassy RJ, et al.: Early enteral feeding compared with parenteral reduces postoperative septic complications. Ann Surg 1992, 2 1 6:172-183.

59. Al-Omran M, Groof A, Wilke D: Enteral versus parenteral nutrition for acute pancreatitis. The Cochrane Database of Systematic Reviews 2003. Art. No. CD002837

60. McGreer AJ, Detsky AS, O'Rourke K: Parenteral nutrition in cancer patients undergoing chemotherapy: a meta-analysis. Nutrition 1990, 6:233-240.

6I. Beghetto MG, Victorino J, Teixeira L, de Azevedo MJ: Parentera nutrition as a risk factor for central venous catheter-related infection. JPEN J Parenter Enteral Nutr 2006, 29:367-373.

62. Sandstrom R, Drott C, Hyltander A, et al.: The effect of postoperative intravenous feeding (TPN) on outcome following 
major surgery evaluated in a randomized study. Ann Surg 1993, 217:185-195.

63. Brennan MF, Pisters PWT, Posner M, Quesada O, Shike M: A prospective randomized trial of total parenteral nutrition after major pancreatic resection for malignancy. Ann Surg 1994, 220:436-444.

64. McCown KC, Fried C, Sternberg J, et al.: Hypocaloric total parenteral nutrition: Effectiveness in prevention of hypoglycemia and infectious complications: a randomized clinical trial. Crit Care Med 2000, 28:3606-36II.

65. Kudsk KA: Current aspects of mucosal immunology and its influence by nutrition. Am / Surg 2002, 183:390-393.

66. Genton L, Kudsk K: Interactions between the enteric nervous system and the immune system: role of neuropeptides and nutrition. Am / Surg 2003, I 86:253-258.

67. Luyer MD, Greve JWM, Hadfoune M, Jacobs JA, Dejong CH, Buurman WA: Nutritional stimulation of cholecystokinin receptors inhibits inflammation via the vagus nerve. J Exp Med 2005, 202: 1023-1029.

68. Wyncoll $D$, Beale R: Immunologically enhanced enteral nutrition: current status. Curr Opin Crit Care 200I, 7:128-132.

69. Beale RJ, Bryg DJ, Bihari DJ: Immuno-nutrition in the critically ill: A systematic review of clinical outcome. Crit Care Med 1999 27:2799-2805.

70. Heys SD, Walker LG, Smith I, Eremin O: Enteral nutritional supplementation with key nutritients in patients with critical illness and cancer. A meta-analysis of randomized controlled clinical trials. Ann Surg 1999, 229:467-477.

71. Braga M, Gianotti L, Radaell G, et al.: Perioperative immunonutrition in patients undergoing cancer surgery. Results of a randomized double-blind phase 3 trial. Arch Surg 1999, 134:428-433.

72. The Food Collaboration: Routine oral nutritional supplementation for stroke patients in hospital (FOOD): a multicentre randomized controlled trial. Lancet 2005, 365:755-763.

73. Olah A, Belagy T, Issekutz A, Gamal ME, Bengmark S: Randomized clinical trial of specific lactobacillus and fibre supplement to early enteral nutrition in patients with acute pancreatitis. Brit J Surg 2002, 89: I I03-I I 07.

74. Van der Huist RMWJ, Van Kreel BK: Glutamine and the presentation of gut integrity. Lancet 1993, 341:1363-1365.

75. Houdijk APJ, Rijnsburger ER, Jansen J, et al.: Randomized trial of glutamine-enriched enteral nutrition on infectious morbidity in patients with multiple trauma. Lancet 1998, 352:772-776.

76. Conejero R, Bonet A, Gran T, et al:: Effect of a glutamineenriched enteral diet on intestinal permeability and infectious morbidity at $\mathbf{2 8}$ days in critically ill patients with systemic inflammatory response syndrome: a randomized, single-blind, prospective, multicenter study. Nutrition 2002, |8:7|6-72|.

77. Wischmeyer PE, Lynch J, Liedel J, et al.: Glutamine administration reduces Gram-negative bacteremia in severely burned patients: A prospective, randomized, double-blind trial versus iso-nitrogenous control. Crit Care Med 200I, 29:2075-2080.

78. Murray SM, Pindoria S: Nutrition support for bone marrow transplant patients. The Chochrane Database of Systematic Reviews 2002. Art. No. CD002920

\section{Publish with Bio Med Central and every} scientist can read your work free of charge

"BioMed Central will be the most significant development for disseminating the results of biomedical research in our lifetime. "

Sir Paul Nurse, Cancer Research UK

Your research papers will be:

- available free of charge to the entire biomedical community

- peer reviewed and published immediately upon acceptance

- cited in PubMed and archived on PubMed Central

- yours - you keep the copyright 